\title{
Ensemble Simulation of Indian Summer Monsoon Rainfall by an Atmospheric General Circulation Model
}

\author{
S. SAJANI \\ Vikram Sarabhai Space Centre, Trivandrum, India \\ T. NAKAZAWA, A. KITOH, and K. RAJENDRAN ${ }^{1}$ \\ Meteorological Research Institute, Tsukuba, Japan \\ (Manuscript received 25 January 2006, in final form 18 January 2007)
}

\begin{abstract}
This study examines the fidelity of the Meteorological Research Institute (MRI) atmospheric general circulation model (AGCM), ensemble runs forced with observed sea surface temperature (SST), in simulating Indian summer monsoon rainfall (ISMR), and its interannual variation. Despite the simple ensemble mean (SEM) capturing essential features of climatological ISMR pattern and its extreme ISMR anomalies, it still shows certain systematic bias in simulating mean seasonal variation of rainfall over the Asia-Pacific region. Concurrently, the ISMR interannual variability throughout the analysis period is not adequately represented.

A bias-correction is applied to remove this bias by deriving weights for the member simulations for each Julian day separately at every grid point through multiple linear regression of their daily rainfall, against corresponding observation over a 23-year 'training phase' (out of the total 24-year analysis period). Thereafter, at every grid point, for each Julian day of the remaining 1-year 'forecast phase', the bias-removed ensemble mean (BREM) is computed as an optimal linear combination of weighted member simulations. In cross validation, each year in the analysis period is treated successively as the 'forecast phase', with the remaining 23 years included in the corresponding training phase. The methodology minimises the systematic bias in mean seasonal variation of rainfall, and BREM consequently improves upon SEM in simulating the mean ISMR pattern, and its interannual variability over the entire analysis period.

The skill of BREM in forecasting the ISMR, and its intraseasonal variability is validated, for the severe monsoon drought of 2002. The effective removal of climatological bias brings out the realistic precipitation response in BREM to fluctuations in SST boundary forcing. As a result, BREM captures the seasonal rainfall anomaly pattern of 2002, and markedly improves its intraseasonal evolution. Apart from the basic skill of the AGCM ensemble system, pronounced equatorial SST impact in modulating the monsoon circulation during 2002 , played a seminal role in the success of the methodology. The analysis also underlines the importance of mean seasonal variation, not only for capturing ISMR climatology, and its interannual variation but for improving its intraseasonal variability as well. With the aid of realistic SST forecasts, this methodology has the application potential for dynamical prediction of ISMR.
\end{abstract}

Corresponding author and present affiliation: S. Sajani, CSIR Centre for Mathematical Modelling and Computer Simulation (C-MMACS), National Aerospace Laboratories (NAL) Belur Campus, Bangalore 560 037, India.

E-mail: sajanirajendran@yahoo.com

(C) 2007, Meteorological Society of Japan
1 Present affiliation: CSIR Centre for Mathematical Modelling and Computer Simulation (C-MMACS), National Aerospace Laboratories, Bangalore, India. 


\section{Introduction}

Over India, most part of the annual rainfall is received during June to September of the summer monsoon season. The majority of the people in the region depend on agriculture for their livelihood, that relies largely on the monsoon rainfall. Since the rainfall is highly seasonal, the time of onset of rainfall, its evolution and the total seasonal rainfall influence agriculture production, hydroelectric power generation, industrial activity and ultimately the whole economy of the country. Although rainfall over India has not shown any decreasing or increasing trend for the last 130 years, it shows considerable interannual variability. The variability is larger over areas of low rainfall leading to floods and droughts, adversely affecting the farming activities of the region. In view of the critical influence of summer monsoon rainfall on the economy, its seasonal forecasting is of great importance.

In India statistical/empirical methods are used for operational seasonal forecasting of summer monsoon rainfall. Over the years several "predictors" have been identified with diagnostic studies of historical data, and these are currently used to issue seasonal forecasts (Rajeevan et al. 2004). Despite the reasonable skill in statistical prediction of Indian summer monsoon rainfall (ISMR), notable failures in ISMR forecasts for extreme years warrant continued efforts using dynamical predictions. Accordingly, experimental attempts are being made to use dynamical models for seasonal forecasting. The major discouraging factor in this effort is the wide range of skill exhibited by atmospheric models in simulating the seasonal mean monsoon, and their inability to adequately represent the interannual variability of monsoon. Several studies on simulating, and predicting monsoon (e.g., Fennessy et al. 1994; Webster et al. 1998; Kang et al. 2002; Waliser et al. 2003; Wang et al. 2005a) have suggested that there are still significant shortcomings in representing the mean monsoon climate, and its variation on different time scales.

The basic premise for forced monsoon simulations using atmospheric general circulation models (AGCMs) is that the seasonal mean tropical circulation is influenced to a large extend by the boundary conditions (Charney and
Shukla 1981), rather than internal dynamics contributed primarily by the interannual variability of the quasi-periodic monsoon lowfrequency intraseasonal oscillation (ISO) comprising the active-break spells. For example, there are several studies, both observational and modeling, which suggest that the interannual variability of ISMR (June to September, JJAS rainfall) is linked to the sea surface temperature (SST) variation in the Pacific (e.g., Ju and Slingo 1995). However, dynamical models are yet to achieve the potential predictability from the external forcing over the tropics (Charney and Shukla 1981; Shukla 1998) despite the immense development over the years (Sperber and Palmer 1996; Gadgil and Sajani 1998). The reasons are primarily their inability to reproduce realistic monsoon precipitation response to pronounced SST fluctuations and partly due to deficient modeling strategy used in forced AGCM simulations (Wang et al. 2005b). However, as general circulation models remain the only plausible tool for short-term climate predictions or long-range forecasts, a comprehensive diagnostic analysis of the simulation of ISMR by GCMs is important for contributing towards the model development to facilitate their use in short-range climate predictions, and deployment as the atmospheric counterpart for climate change studies.

In this context, the present study focuses on the utility of the Meteorological Research Institute (MRI) AGCM ensemble system, for dynamical seasonal prediction of ISMR. In the first part, the reproducibility of the MRI ensemble system, in simulating the climatological ISMR pattern, and its interannual variation, is assessed. Varying roles of external forcing (signal), and internal dynamics (noise), in influencing the interannual variability of ISMR (Goswami 1998) make the simulation of Indian monsoon a challenging problem for the AGCMs. Hence, suitable methods have to be devised to extract the signal, due to external forcing from the noise of almost equal amplitude. Monsoon diagnostic study of Gadgil and Sajani (1998), using Atmospheric Model Intercomparison Project (AMIP) simulations, suggested that realistic mean seasonal variation of rainfall over the tropical Asia-Pacific sector (which is characterised by maximum latitudinal migration of the primary rainbelt from winter to summer 
season), is important not only for capturing ISMR interannual variation, but for achieving a realistic simulation of climatological ISMR pattern as well. In the light of the outcome of this study, a suitable bias correction method that can effectively minimize the bias in the simulation of climatological seasonal variation of rainfall is devised, following the superensemble methodology (Krishnamurti et al. 1999).

The model, ensemble integrations and validation datasets are described in Section 2. Importance of climatological seasonal variation of rainfall over the Asia-Pacific sector, and the skill of the ensemble mean simulation in capturing these aspects, are presented in Section 3. In Section 4, climatological bias-removal methodology and the performance of biasremoved ensemble mean in simulating climatological aspects, and ISMR interannual variability are discussed. In Section 5, the skill of the bias-removed ensemble mean in simulating ISMR pattern, and intraseasonal variability during a representative extreme event of 2002 is illustrated. Discussion and concluding remarks are given in Section 6.

\section{Model, ensemble integrations and datasets}

The MRI AGCM (MJ98) used in this study is based on the modified climate research version of earlier operational forecast model of the Japan Meteorological Agency, the details of which are given in Shibata et al. (1999). The model with comprehensive physics parameterizations has T42 horizontal resolution corresponding to $\sim 2.8^{\circ}$ on transform grid, with 30 vertical layers extending up to $0.4 \mathrm{hPa}$.

\subsection{Ensemble integrations}

The MRI AGCM ensemble system consists of 12 integrations performed using slightly different initial conditions. The integrations were performed from 1951 to 2002, forcing the model with observed SST and sea ice data from 'HadISST1' (Rayner et al. 2003). As for greenhouse gases, the observed concentration of $\mathrm{CO}_{2}$ is adapted from Hansen et al. (2002), increasing from $311 \mathrm{ppmv}$ in 1951 to $370 \mathrm{ppmv}$ in 2001. This was given homogeneously to the whole atmosphere without any seasonal cycle. The concentrations of $\mathrm{CH}_{4}(1650 \mathrm{ppbv})$ and $\mathrm{N}_{2} \mathrm{O}$ (306 ppbv) are kept constant in time and space. Out of the 52 year ensemble simulations, simulations for the period 1979-2002, coinciding the availability of Global Precipitation Climatology Project (GPCP) pentad precipitation, are selected for the analysis. A simple ensemble mean is used to reduce uncertainties arising from the sensitivity to small changes in initial conditions, minimize weather noises and enhance climate signal. The simple average of all member simulations for each day and each grid point is hereafter referred to as the 'simple ensemble mean' (SEM) simulation.

\subsection{Datasets}

Validation datasets used in this study are daily NCEP/NCAR reanalysis datasets (Kalnay et al. 1996), daily SSTs interpolated from 1982-2002, Reynold's weekly SSTs (Reynolds et al. 2002), and monthly NOAA OI.v2 SST datasets (Reynolds and Smith 1994). A combined data set of daily rainfall estimates interpolated from GPCP pentad precipitation data for the period 1979-1997 (Xie et al. 2003), and daily 3B42 TRMM-adjusted merged-infrared precipitation (Version 5) for 1998-2002 (Alder et al. 2002), are used for precipitation validation (hereafter referred to as 'GPCP' data). Daily raingauge observations over Indian landmass, based on COLA GTS data (http://www .monsoondata.org) for the period 1979-2002, is also used in this study.

\section{Climatological seasonal variation}

The ability of AGCMs to realistically simulate the seasonal variation of precipitation over tropical regions has been the object of many studies. For example, the AMIP analysis of Gadgil and Sajani (1998) has suggested that those AMIP models, which realistically simulate the seasonal transition of primary rainbelt over the tropical Asia-Pacific region, are not only more adept at simulating the seasonal mean pattern of ISMR, but also are successful in reproducing the year to year variation of allIndia summer monsoon rainfall (ISMR) associated with major El Niño/La Niña events. Figure 1 shows observed climatological summer (JJAS) mean precipitation over the Indian region, and latitudinal variation of climatological mean precipitation averaged over the AsiaPacific $\left(70^{\circ} \mathrm{E}-140^{\circ} \mathrm{E}\right)$ region. The mean summer monsoon rainfall distribution exhibits multiple 
(a)

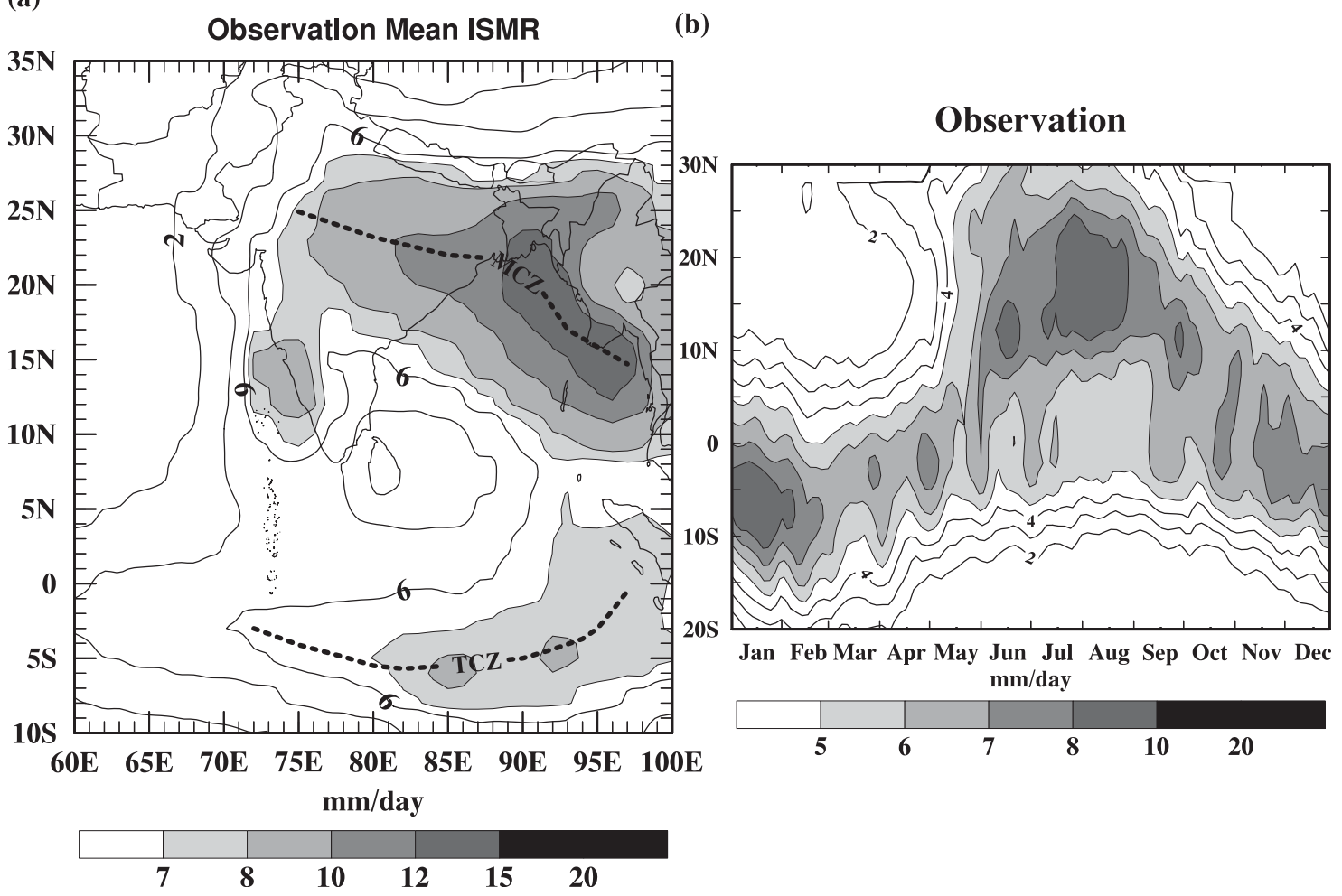

Fig. 1. Observed (a) climatological JJAS mean precipitation over the Indian region and (b) the latitudinal variation of climatological mean precipitation averaged over the Asia-Pacific $\left(70^{\circ} \mathrm{E}-140^{\circ} \mathrm{E}\right)$ region.

favorable positions for tropical convergence zone (TCZ) to occur over the Indian region. These TCZs are the regions characterized by organized convection in a sustained manner on seasonal time scales. Among these TCZs, the primary rainbelt over the monsoon convergence zone (MCZ) coincides the seasonal mean location of the monsoon trough over India. This extends westwards from the Head Bay of Bengal, across the Indo-Gangetic plane. In addition, there is a secondary rainbelt over the equatorial Indian Ocean (highlighted by dashed line in Fig. 1a), and intense orographic rainfall occurs along the west coast and over the Himalayas.

The mean seasonal variation of rainfall averaged over the Asia-Pacific sector (Fig. 1b) shows the seasonal migration of the primary rainbelt from the southern equatorial region in Boreal winter to northern hemisphere in Boreal summer. Over the tropics this is the region that experiences maximum amplitude of latitu- dinal migration of the primary rainbelt from winter to summer as part of the seasonal march of the Inter-Tropical Convergence Zone (ITCZ). Analysis of around 30 AMIP models by Gadgil and Sajani (1998) suggested that realistic representation of the seasonal transition of primary rainbelt over this region is essential for capturing the ISMR interannual variation, and improving the climatological seasonal mean rainfall pattern over India. Another notable feature in the mean annual cycle of rainfall averaged over the Asia-Pacific sector is the pronounced subseasonal fluctuation in maximum rainfall in a time scale of over a month evident throughout the cycle.

Figure 2 shows SEM simulation of climatological JJAS mean rainfall over the Indian region, and latitudinal variation of climatological precipitation averaged over the Asia-Pacific region $\left(70^{\circ} \mathrm{E}-140^{\circ} \mathrm{E}\right)$. SEM captures the essential features, such as the extent and location of prominent rainbelts over the Indian region dur- 
(a)
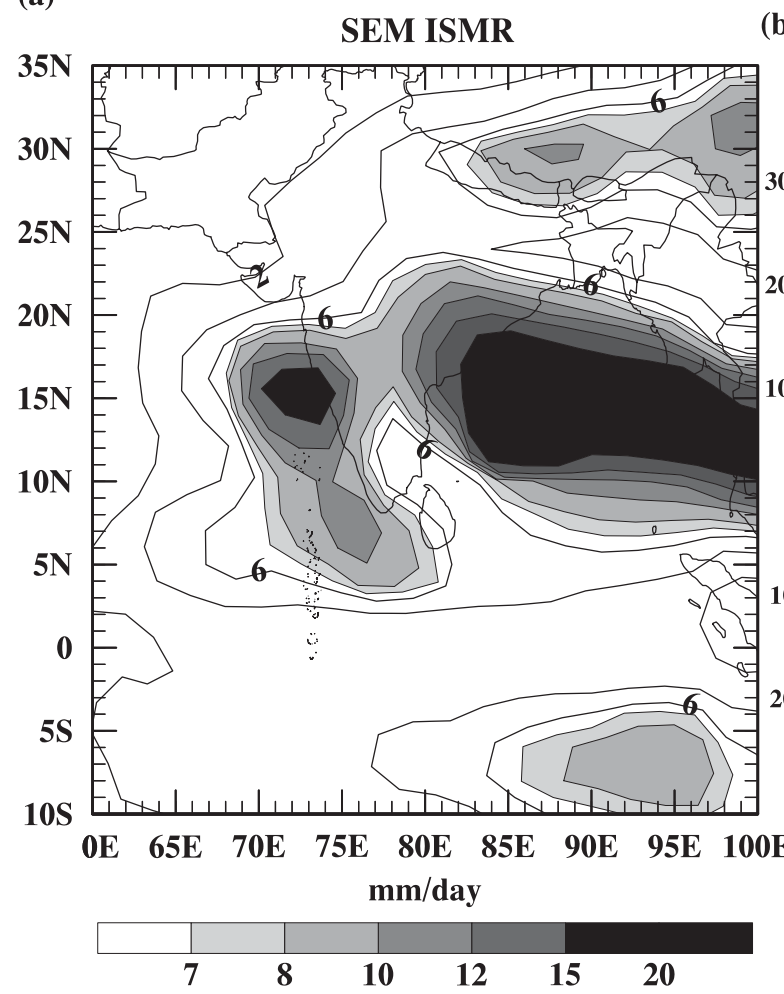

(b)

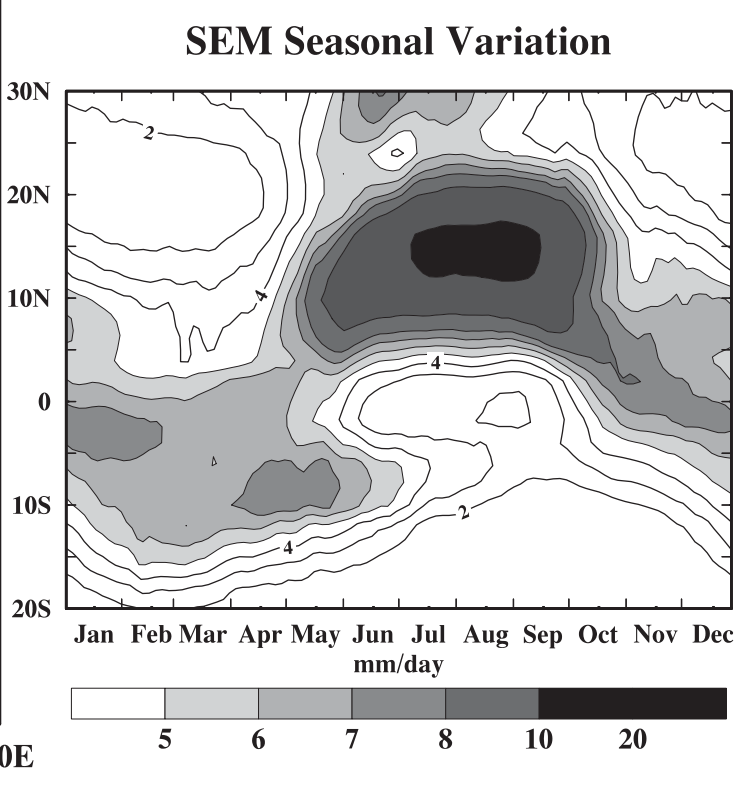

Fig. 2. The simple ensemble mean (SEM) simulation of (a) climatological JJAS mean precipitation over the Indian region and (b) the latitudinal variation of climatological mean precipitation averaged over the Asia-Pacific $\left(70^{\circ} \mathrm{E}-140^{\circ} \mathrm{E}\right)$ region.

ing the summer monsoon season, especially the rainbelt over the MCZ across the Indo-Gangetic plane. However, the orientation of these TCZs slightly differ from observation (Fig. 1a), and systematic overestimation of maximum rainfall is evident over all the convective centres. The seasonal migration of the primary rainbelt over the Asia-Pacific region from southern equatorial region in northern winter to the northern hemisphere in summer is simulated well. However, the simulation appears to be smoother with overestimated rainfall devoid of realistic subseasonal fluctuations. Unlike observation, the simulated primary rainbelt in the summer, appears to be persistent around $15^{\circ} \mathrm{N}$. Note that subseasonal fluctuations in mean annual cycle were not seen in any of the ensemble member simulations. Hence, the smooth annual cycle without subseasonal fluctuations seen in the simple ensemble mean is not an artifact of ensemble averaging.

\section{Bias-removal methodology}

Considering the importance of climatological seasonal variation of rainfall over the AsiaPacific sector for the simulation of interannual variation of ISMR, an effective method is applied on rainfall from all member simulations for each Julian day at each grid point, to remove the systematic bias in the climatological seasonal variation of rainfall. The method is based on multiple regression of member simulations against observation over a training phase, following the superensemble technique (Krishnamurti et al. 1999; Krishnamurti et al. 2000; Krishnamurti et al. 2001). In this method, the total analysis/simulation period is divided into two phases, a training phase, and a forecast phase. In the training phase, the weights (regression coefficients) for each member simulation is determined through the least-squares minimization of the difference be- 
tween the simulated rainfall and observation. This minimization is carried out for all 365 Julian days separately at all grid points over the tropical Asia-Pacific sector.

In the present study, the 24-year analysis period is divided into a 23-year training phase, and 1-year forecast phase. In cross validation, each year in the 24-year analysis period is considered successively as the 'forecast phase', with the remaining 23 years included in their training phase. Thus, for each Julian day, at a given grid point, there are a total of 24 days in the analysis period of 1979-2002, out of which 23 days are treated as the training period, to obtain the weights for member simulations, and the remaining 1 day is considered as the forecast phase. In the training phase, weights are calculated for each Julian day of the 365 day calendar, at a given grid point. Accordingly, in the forecast phase, for each Julian day, the 'bias-removed ensemble mean' is computed as the sum of model forecast anomalies for that day weighted by the corresponding coefficient (statistics derived over the training period), and added to the observed mean rainfall over the training period for that day. For example, for forecasting 3 February 2002, the training period has 23 days viz., 3 February 1979, 3 February 1980, 3 February 1981, up to 3 February 2001. The coefficients for the member simulations are derived through regression of the training day simulations against the corresponding 23-day observation. The coefficients obtained for the members, observed mean for 3 February over the training period, and simulated anomalies for 3 February 2002 from the members (computed as the departure from their training period mean for 3 February) are utilized to obtain the 'bias-removed ensemble mean' (hereafter referred to as BREM) simulation. Similarly, in cross validation, 3 February 2000 forecast will have 23-day training period, comprising 3 February 1979, 3 February 1980, 3 February 1981 up to 3 February 1999, 3 February 2001 and 3 February 2002.

Thus, for a Julian day in a forecast year, BREM is given as,

$$
\operatorname{BREM}_{j}=\overline{O_{j}}+\sum_{i=1}^{N} \alpha_{i j}\left(F_{i j}-\overline{F_{i j}}\right),
$$

where $j$ is the Julian day index (ranging from
1 to 365), $i$ is the ensemble member index, $N$ is the total number of ensemble simulations (which is equal to 12 ), $\overline{O_{j}}$ is the time mean of the observed state over the training phase for $j^{\text {th }}$ Julian day, $\alpha_{i j}$ is the regression coefficient of $i^{t h}$ member for $j^{\text {th }}$ Julian day derived through regression against observation during the training phase, $F_{i j}$ is $i^{\text {th }}$ member rainfall simulation for $j^{\text {th }}$ Julian day of forecast year, and $\overline{F_{i j}}$ is the corresponding $j^{\text {th }}$ Julian day mean rainfall over the training phase. The weights $\alpha_{i j}$ for the members are computed at a given grid point, and for each Julian day through multiple linear regression during the training phase by minimizing the following function:

$$
G=\sum_{t=1}^{t_{\text {training }}}\left(B R E M_{t}-O_{t}\right)^{2}
$$

where $t$ denotes time and $t_{\text {training }}$ is the total number of training days (which is equal to 23). This procedure is applied at every grid point over the tropical Asia-Pacific region to effectively remove the bias in the simulation of mean seasonal variation of rainfall in the members, through nudging towards $\overline{O_{j}}$ of a training phase.

The BREM simulated climatological summer mean precipitation over the Indian region and the latitudinal variation of mean precipitation averaged over the Asia-Pacific region $\left(70^{\circ} \mathrm{E}-\right.$ $140^{\circ} \mathrm{E}$ ), are shown in Fig. 3. The strength and orientation of all the TCZs compare well with the observation (Fig. 1a). The location and intensity of the primary monsoon rainbelt over central India, the secondary oceanic rainbelt, and rainfall over the orographic regions are markedly improved (Fig. 3a). Similarly, the seasonal variation of rainfall over the AsiaPacific region is improved remarkably (Fig. $3 b)$. The amplitude of the latitudinal transition from winter to summer is closer to the observation compared to the SEM simulation. More importantly, the BREM reproduces realistic subseasonal fluctuations of rainfall, as seen in observation. This shows that the bias removal technique is effective. It successfully captures the mean seasonal variation of rainfall over the tropical Asia-Pacific region, and thereby improves the simulation of important features of climatological ISMR pattern. 
(a)

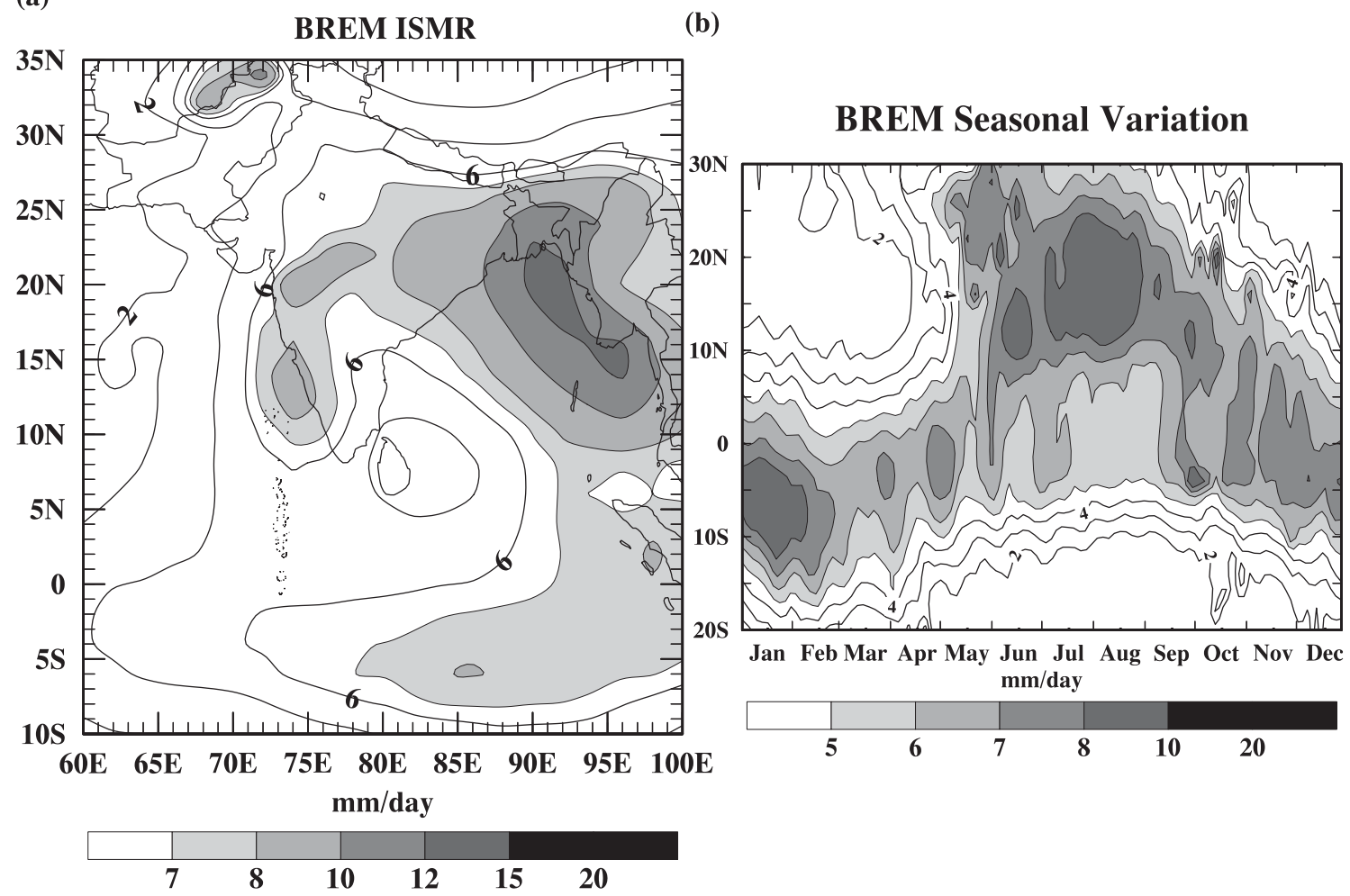

Fig. 3. Bias-removed ensemble mean (BREM) simulation of (a) climatological JJAS mean precipitation over the Indian region and (b) the latitudinal variation of climatological mean precipitation averaged over the Asia-Pacific $\left(70^{\circ} \mathrm{E}-140^{\circ} \mathrm{E}\right)$ region.

The effective removal of systematic bias in the mean seasonal variation helps to improve the interannual variation over the entire analysis period. For example, cross validation of extreme years indicates remarkable improvement

Table 1. All-India seasonal (JJAS) mean rainfall departure expressed as percentage of its climatological value for years associated with prominent El Niño (denoted as ' $\mathrm{E}$ ') and La Niña (denoted as ' $L$ ') events from IMD observation, GPCP data, and simple ensemble mean (SEM) and bias-removed ensemble mean (BREM) simulations.

\begin{tabular}{lrrrr}
\hline \hline Year & IMD & GPCP & SEM & BREM \\
\hline $1982(\mathrm{E})$ & -15 & -12.2 & -8.3 & -8.9 \\
$1987(\mathrm{E})$ & -16 & -21.6 & -3.4 & -10.3 \\
$1988(\mathrm{~L})$ & 19 & 9.4 & 12.1 & 12.4 \\
$1997(\mathrm{E})$ & 3 & 2.5 & 1.5 & 2.6 \\
\hline \hline
\end{tabular}

in capturing the seasonal anomaly over India by the BREM simulation. Table 1 shows the ISMR departures associated with prominent El Niño/La Niña events from the India Meteorology Department (IMD) raingauge observation (hereafter referred to as IMD data), GPCP data, and the SEM and the BREM simulations. There are slight quantitative differences between the GPCP based ISMR departures, and the IMD observed record of Parthasarathy et al. (1994). But the amplitude and sign of major ISMR extremes associated with pronounced Pacific SST fluctuations are markedly improved in the BREM compared to the SEM, when validated against both of the GPCP data (which is used as benchmark data to compute the BREM) and the IMD data. Whereas, in the SEM, though the extreme ISMR anomalies are qualitatively simulated, there exist significant shortcomings in representing the interannual variability over the whole analysis period. Figure 4 shows the interannual variation of the 


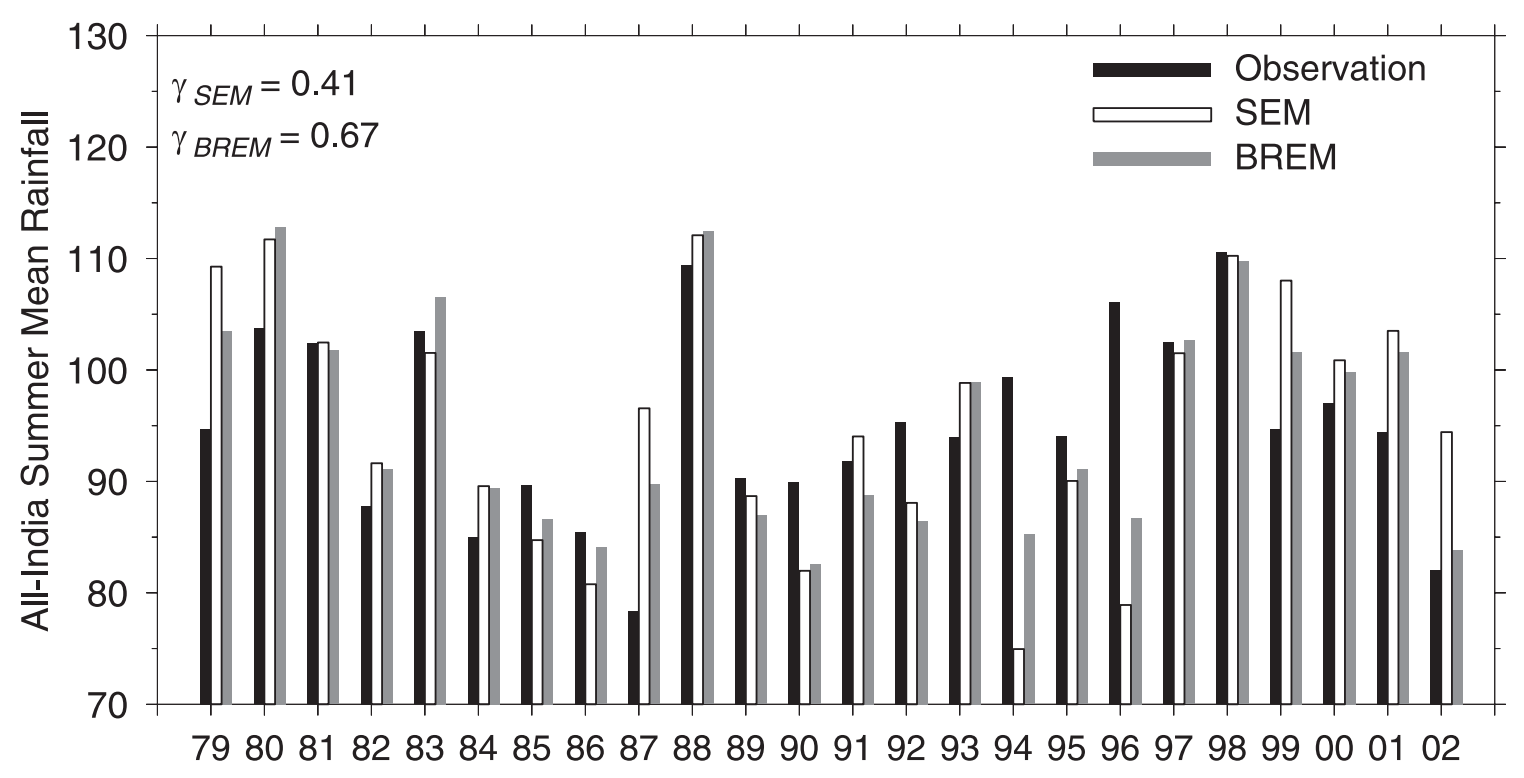

Fig. 4. Interannual variation of ISMR from observation, simple ensemble mean (SEM) and bias-removed ensemble mean (BREM) simulations. All-India seasonal (JJAS) mean rainfall for each year is expressed as percentage of its long-term mean.

ISMR from the GPCP data and the SEM and the BREM simulations. All-India seasonal (JJAS) mean rainfall (estimated as the total JJAS precipitation over all land grid boxes over the Indian region) for each year, is expressed as the percentage of the long-term allIndia mean ISMR. The correlation coefficient for the SEM is 0.41 where the correlation significant at $95 \%$ level is 0.3 . In contrast, the essential features of the ISMR interannual variability throughout the analysis period are better represented in the BREM simulation. The amplitude and sign of the ISMR departures are closer to observed benchmark analysis with a marked improvement in the correlation coefficient which is 0.67 .

\section{Validation of bias-removed ensemble mean}

Further, the impact of climatological biasremoval on forecasting the ISMR evolution is assessed by analyzing the forecasting skill of BREM, during a representative extreme ISMR event.

\subsection{Seasonal mean rainfall}

An abnormal Indian summer monsoon of 2002 is the most severe drought recorded in recent times, with the rainfall being 19\% below the long term normal ISMR. Here, a detailed assessment of the forecasting skill of BREM in simulating this seasonal anomaly is presented, and subseasonal evolution of this severe drought monsoon. Apart from the anomalously low seasonal rainfall, the remarkably different nature of the onset and evolution of monsoon during this year made a compelling reason for undertaking this case study. In forecasting the 2002 season, the bias-removed ensemble mean is constructed as an optimal linear combination of weighted simulations of daily rainfall for 2002, where the weights for individual member simulations at each grid point for each Julian day of 2002 were obtained through the regression of member simulations against observation during the training phase of 1979-2001.

Observed seasonal (JJAS mean) rainfall departure during 2002 (expressed as percentage of JJAS mean rainfall climatology) shows that severe drought conditions prevailed over most of the Indian subcontinent (Fig. 5a). Over large areas in western India, and the southern peninsula, the monsoon rainfall was deficient by more than $30 \%$ of the normal. At the same time of the widespread decrease of seasonal 
(a)

Observation
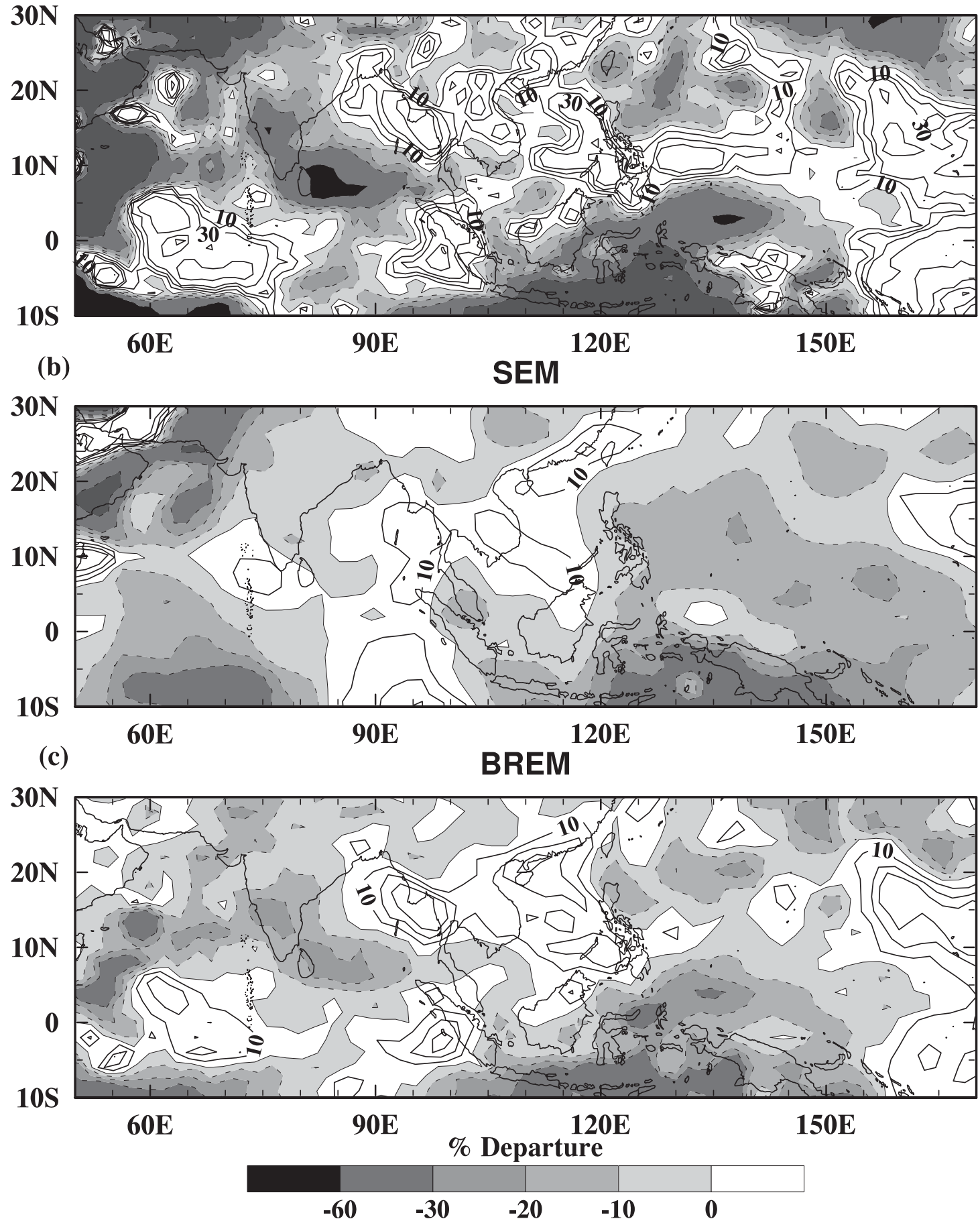

Fig. 5. The 2002 seasonal (JJAS mean) rainfall departure as percentage of climatological JJAS mean rainfall from (a) GPCP data, and (b) simple ensemble mean (SEM) and (c) bias-removed ensemble mean (BREM) simulations. 


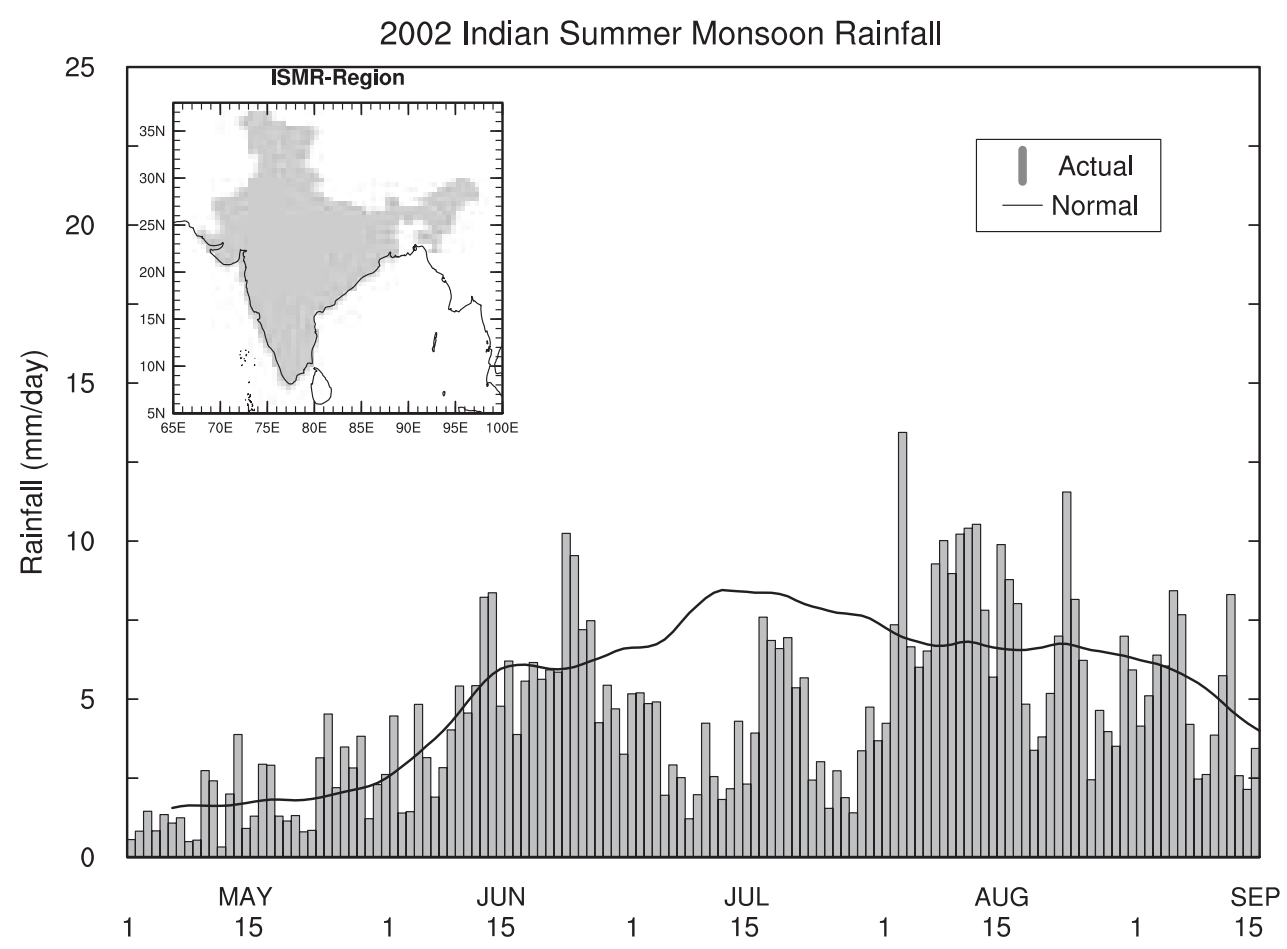

Fig. 6. Daily mean all-India (region highlighted in the inset map) average rainfall during the 2002 summer season from COLA GTS data. Daily long term mean is represented by the solid line.

monsoon rainfall over land, the equatorial Indian Ocean (EQIO) experienced intense rainfall anomalies, more than $20 \%$ of normal, extending longitudinally across most of the ocean basin. The maximum value of the anomaly is close to $50 \%$ around the equator over $60^{\circ} \mathrm{E}-75^{\circ} \mathrm{E}$. Although the SEM simulates negative anomalies over the Indian landmass (Fig. 5b), the magnitude and regional distribution is better simulated in the BREM (Fig. 5c). The marked improvement is evident not only over the Indian landmass, but over EQIO and west Pacific Ocean as well. This clearly implies the crucial impact of removal of climatological bias in improving the monsoon precipitation response in the model. Removal of the mean bias clearly brings out the precipitation response of the ensemble system to the given SST boundary forcing. The influence of SST on 2002 ISMR is discussed in detail in the last section.

\subsection{Intraseasonal variability}

Anomalous seasonal rainfall over India in 2002 was due to the special nature of subseasonal evolution of ISMR. Daily variation of 2002
all-India summer monsoon rainfall (Fig. 6), based on COLA GTS data, comprising raingauge estimates over the Indian landmass (highlighted in the inset India Map), distinctly shows the special nature of the onset and evolution of monsoon observed during 2002 summer season. A notable aspect of 2002 season is the false onset (Ananthakrishnan and Soman 1988; Joseph et al. 1994; Flatau et al. 2003) where the false onset occurs around 11 May, with mild and intermittent rainfall continuing until around 28 May. The region experiences a dry spell afterwards which results in a late onset of bountiful monsoon rains over India compared to the climatological onset date in the end of May/beginning of June. The real onset of rainfall occurs around mid-June, that persists until the last week of June. The primary feature of the season is the intense and long dry spell extending from the end of June until the beginning of August. Finally the season experiences an early withdrawal of monsoon, facilitated by a long break spell, starting from the second week of September.

The fluctuations in monsoon activity within 
(a)

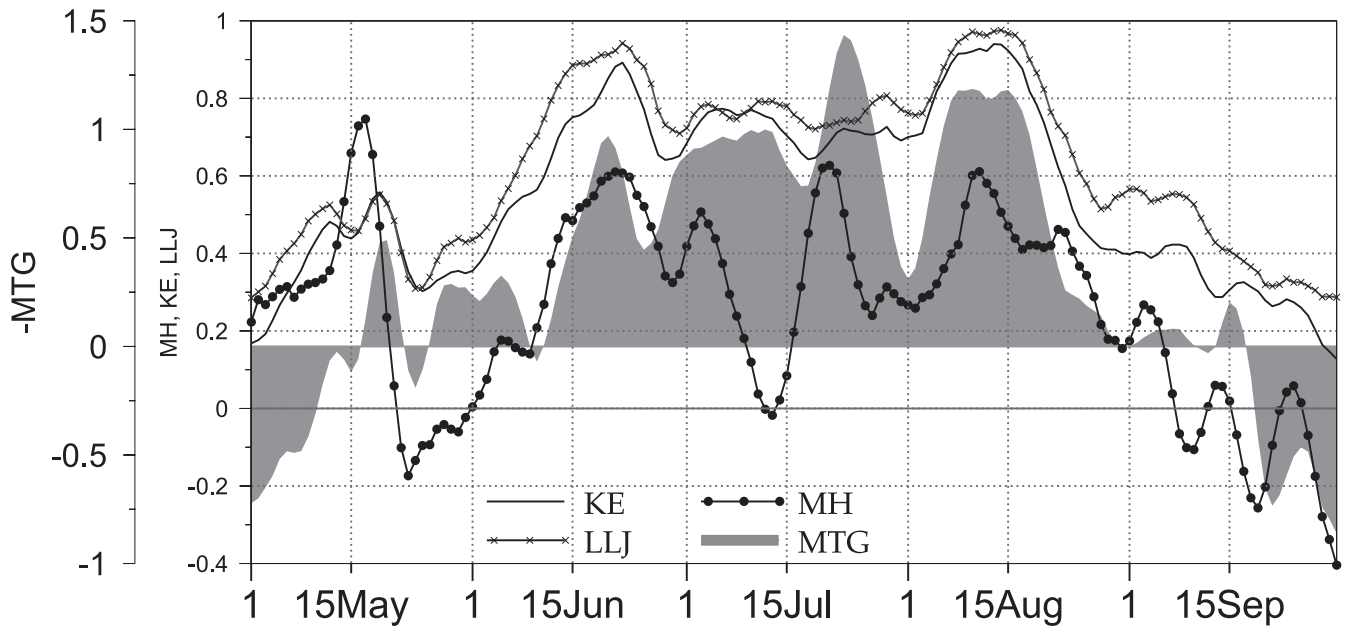

(b)

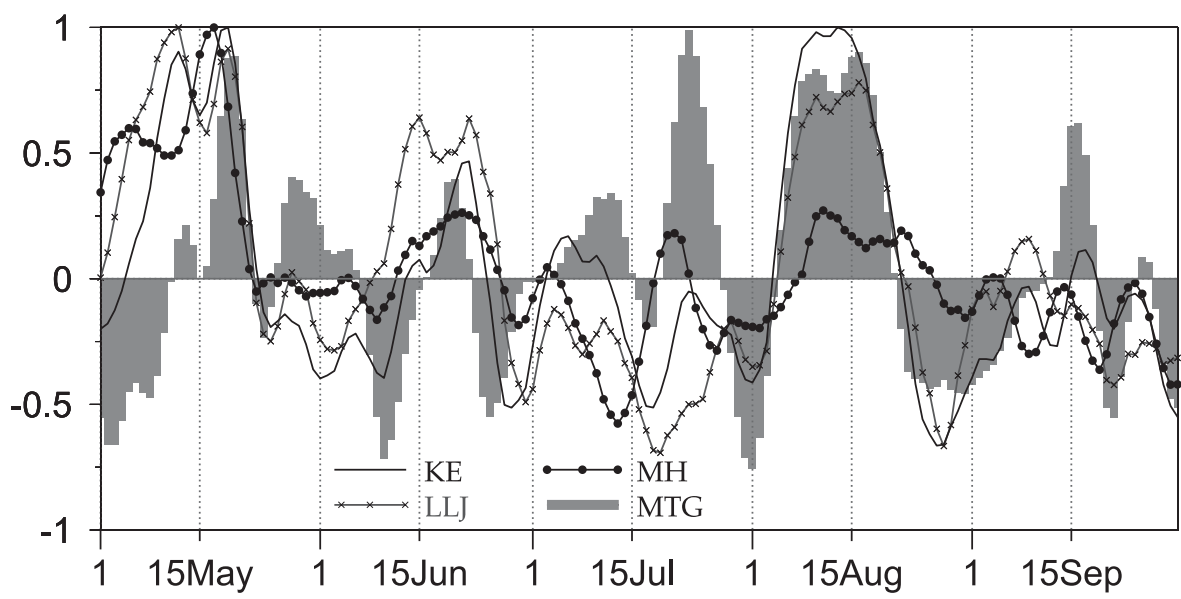

Fig. 7. Daily (normalized with respect to daily long-term mean and then smoothed using 5 day running mean) time series of (a) actual and (b) anomalies of different monsoon indices, during the 2002 Indian summer monsoon season.

the season is evidently seen in different monsoon indices representing intraseasonal fluctuations in monsoon circulation. These indices are the monsoon circulation index $(\mathrm{MH}$, based on the strength of the local Hadley cell, created by the off-equatorial monsoon heating, is defined as the shear between 850 and $200-\mathrm{hPa}$ meridional winds, averaged over $10^{\circ} \mathrm{N}-30^{\circ} \mathrm{N}$; $70^{\circ} \mathrm{E}-110^{\circ} \mathrm{E}$, Goswami et al. 1999), kinetic energy (KE) of the surface winds averaged over $5^{\circ} \mathrm{N}-20^{\circ} \mathrm{N} ; 40^{\circ} \mathrm{E}-110^{\circ} \mathrm{E}$, the strength of crossequatorial flow associated with the low-level
Somali jet (LLJ, based on the $850-\mathrm{hPa}$ wind speed averaged over $5^{\circ} \mathrm{N}-20^{\circ} \mathrm{N} ; 50^{\circ} \mathrm{E}-80^{\circ} \mathrm{E}$ ), and the meridional temperature gradient index [MTG, based on the difference in area-averaged upper tropospheric $(500-200 \mathrm{hPa})$ thickness between the Tibetan Plateau $\left(20^{\circ} \mathrm{N}-40^{\circ} \mathrm{N}\right.$; $\left.50^{\circ} \mathrm{E}-100^{\circ} \mathrm{E}\right)$, and the Indian Ocean $\left(0^{\circ} \mathrm{N}-\right.$ $\left.20^{\circ} \mathrm{N} ; 50^{\circ} \mathrm{E}-100^{\circ} \mathrm{E}\right)$ regions, Kawamura 1998$]$.

Actual (normalized with respect to daily longterm mean over the last 30 year period) and anomalies of these indices for 2002 monsoon season are shown in Figs. $7 \mathrm{a}$ and $7 \mathrm{~b}$. The pri- 


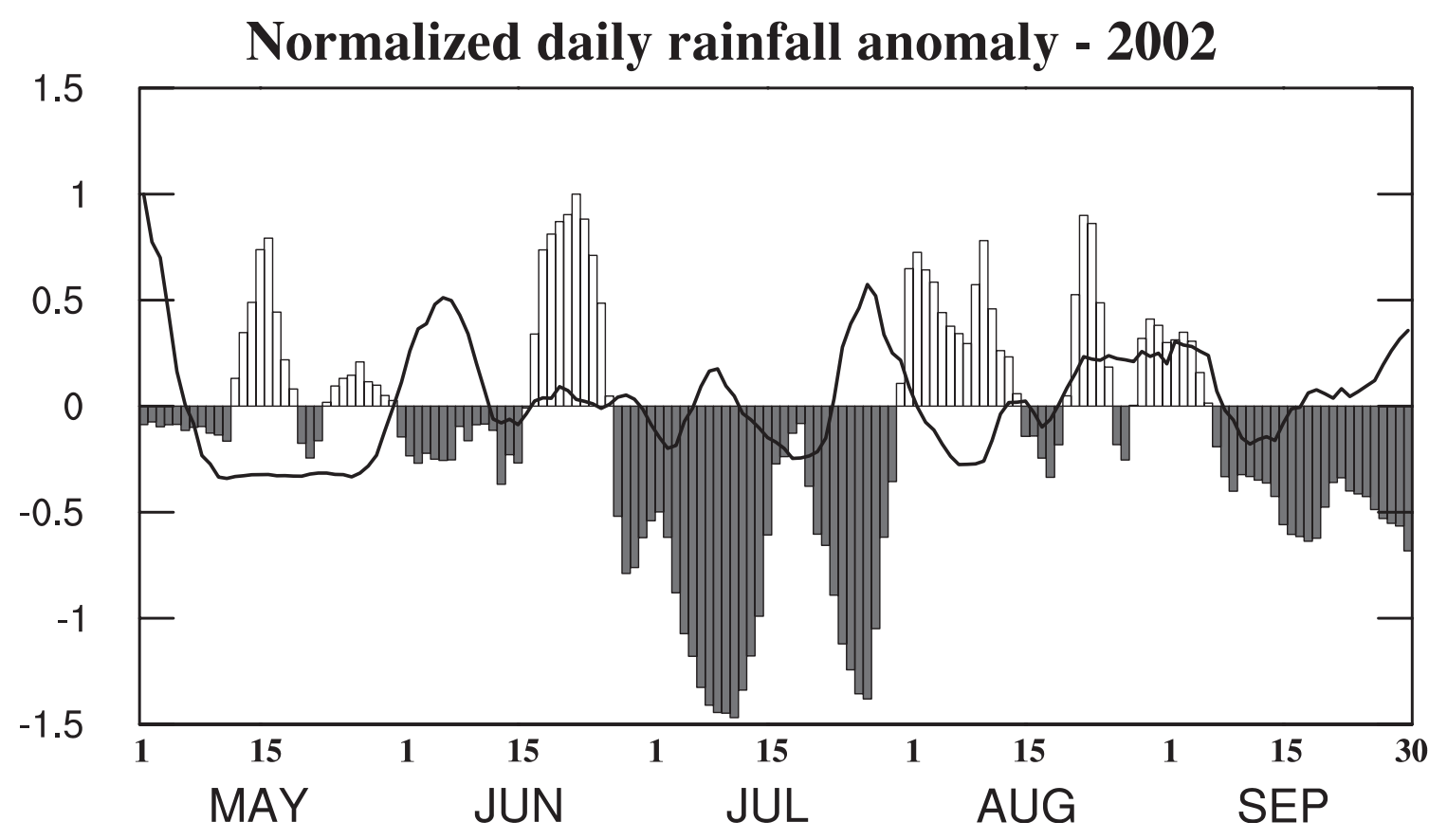

Fig. 8. Normalized and smoothed daily rainfall anomalies during the 2002 summer season from GPCP observed benchmark analysis. The bars represent average over the central Indian region (MCZ) and the solid line represents the average over the equatorial Indian Ocean (EQIO).

mary feature is the pronounced fluctuations in $\mathrm{MH}$, LLJ and KE, and to some extent in MTG that are markedly consistent with the ISMR fluctuations (Fig. 6), where epochs of enhanced and weakened amplitudes of different indices (Fig. 7b), correspond well with the active and break spells of ISMR. These variations indicate significant subseasonal modulations in the local Hadley circulation and the meridional land-ocean temperature contrast associated with Indian summer monsoon. The peaks of the indices in mid-May corresponds to the false onset, and the peaks in mid-June corresponds to the real onset. The weakening of large-scale monsoon circulation parameters during July, till the beginning of August, corresponds to the intense break spell and the revival afterwards coincides with the short active spell in the first week of August. The indices show weakening of large-scale monsoon circulation after the first week of September. Another notable aspect is the difference in actual monsoon indices between the false and real onset of monsoon (Fig. 7a). Unlike for the false phase, the actual indices show a sharp and sustained strengthening that lasts, until the withdrawal, for the real onset. Whereas, during the false onset, the indices do not show a sustained increase in amplitude, due to the lack of organized seasonal change in different forcing factors of monsoon.

Evolution of the 2002 monsoon in the GPCP benchmark analysis, used for training the member simulations is important in assessing the skill of the BREM simulation. Daily anomalies averaged over Central India $\left(15^{\circ} \mathrm{N}-25^{\circ} \mathrm{N}\right.$; $75^{\circ} \mathrm{E}-85^{\circ} \mathrm{E}$, coinciding the $\mathrm{MCZ}$ ) and EQIO $\left(10^{\circ} \mathrm{S}-5^{\circ} \mathrm{N} ; 50^{\circ} \mathrm{E}-100^{\circ} \mathrm{E}\right)$ show all the major characteristics of the 2002 season viz. the false onset, intense break in July, and the short duration of monsoon (Fig. 8). The rainfall variation over the MCZ in the GPCP data closely corresponds to the observed active and break phases (Fig. 6), characterized by enhanced and reduced precipitation over central India along with associated changes in large-scale circulation (Fig. 7). A notable feature is the nearinverse rainfall variation, between the $\mathrm{MCZ}$ and EQIO throughout the summer season with increased (decreased) rainfall over EQIO, mostly associated with decreased (increased) 
(a)

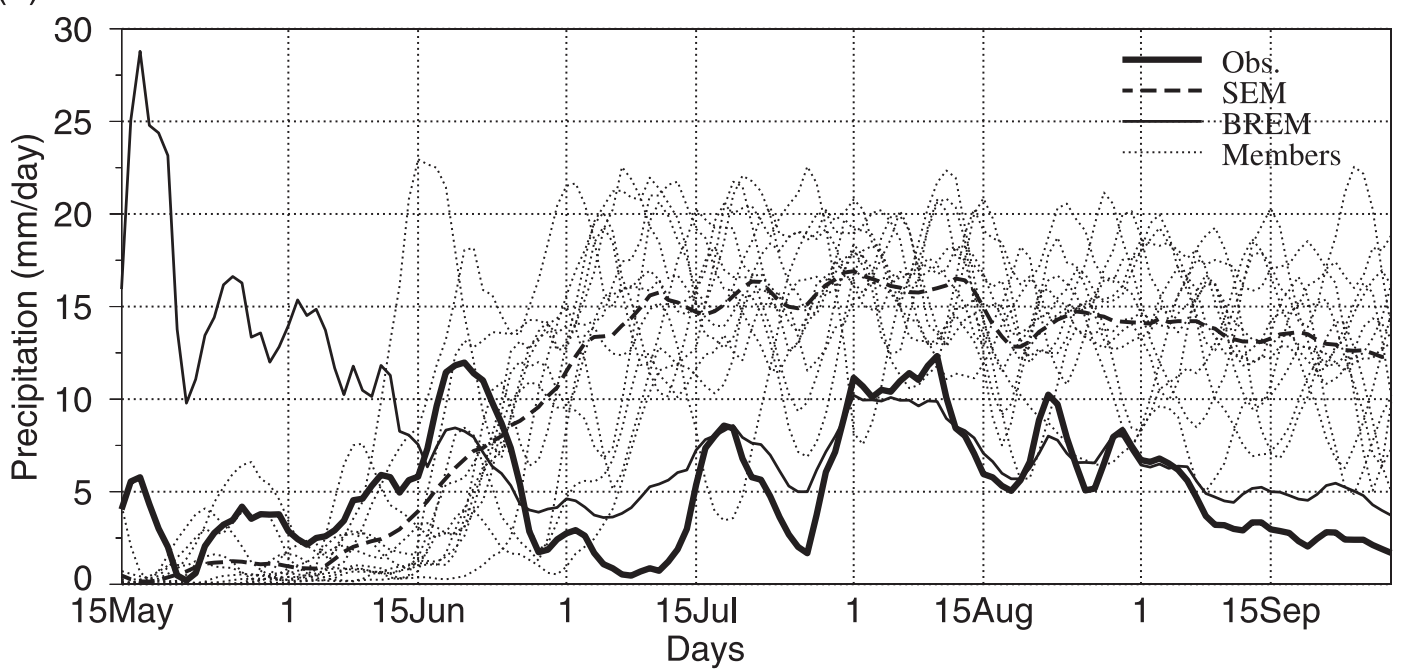

(b)

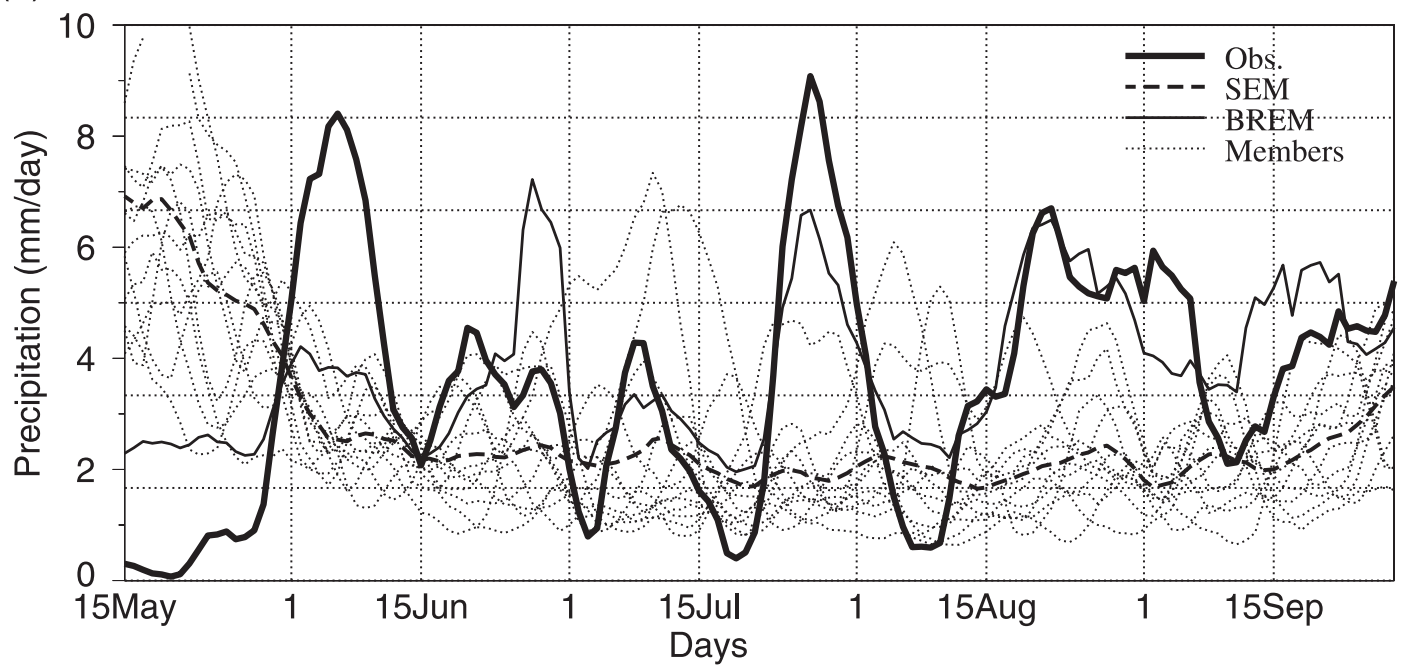

Fig. 9. The 5-day running mean applied time series of daily rainfall averaged over MCZ and EQIO from observation, member simulations, and simple ensemble mean (SEM) and bias-removed ensemble mean (BREM) simulations.

rainfall over the MCZ. This can be understood in terms of the waxing and waning of the two limbs of the monsoon reverse Hadley cell, one over the warm equatorial Indian Ocean, and the other over the heated continent in the north.

To assess the simulation skill of BREM, daily variation of observed and simulated rainfall (after applying a 5-day running mean) over the $\mathrm{MCZ}$ and the equatorial Indian Ocean (EQIO), during the 2002 Indian summer monsoon season are shown in Fig. 9. It can be clearly seen that marked improvement is achieved in BREM, in capturing the amplitude and phase of subseasonal variation of rainfall over the MCZ, after the real onset and over the EQIO throughout the season after the removal of mean bias. Over MCZ, the SEM simulated rainfall gradually increases with the advancement of summer with a trend different from observation. In contrast, the variations in BREM is close to observation, except for the false onset period. During the false onset, the BREM overestimates rainfall over the MCZ mainly due to 
the contribution from $\bar{O}$ term in its estimation (Eq. 1). $\bar{O}$ over the MCZ is higher during this time, due to the several 'false onset' years (Flatau et al. 2001), during the training phase of 1979-2001. Despite this overestimation the nature of variation in the BREM in this phase, and later throughout the season, closely follows the corresponding observation. Over the EQIO the rainfall variation in the SEM is smooth, with very little subseasonal fluctuation. Whereas the amplitude, and phase variation in the BREM are in fairly good agreement with the observed subseasonal fluctuations, particularly from the second half of June.

\subsection{Low-frequency intraseasonal oscillation}

The dominant intraseasonal oscillation in 2002 was on low-frequency intraseasonal time scales, and the most pronounced mode was the northward propagating intraseasonal oscillations (Sajani et al. 2007). This intraseasonal mode is characterised by successive $30-40$ day time scale northward propagations of organized convection over the Indian sector in summer (Sikka and Gadgil 1980; Yasunari 1979, 1981). The time-latitude variation of 20-80 day band pass filtered (following Duchon 1979) observed GPCP rainfall, averaged over the Indian longitudes (Fig. 10a), shows the close correspondence between propagating signals of active convection and the onset, active/break phases and withdrawal of monsoon (Fig. 8). The false onset was characterized by a propagating rainbelt from the equatorial Indian Ocean reaching the southern peninsula in early May. Later, the real onset of heavy precipitation over India by the middle of June coincides with the next propagating anomaly reaching the central Indian latitudes. The intense break spell during July, and after the first week of September, are associated with prolonged periods of suppressed convection and absence of any active propagations.

Corresponding northward propagations from the SEM and the BREM simulations are shown in Figs. 10b and 10c respectively. While there are no coherent propagations evident in the SEM, distinct and coherent propagations matching the observation to a great extent, exist in the BREM. Also, compared to the SEM, there is a good correspondence between observed, and the BREM simulated propagations

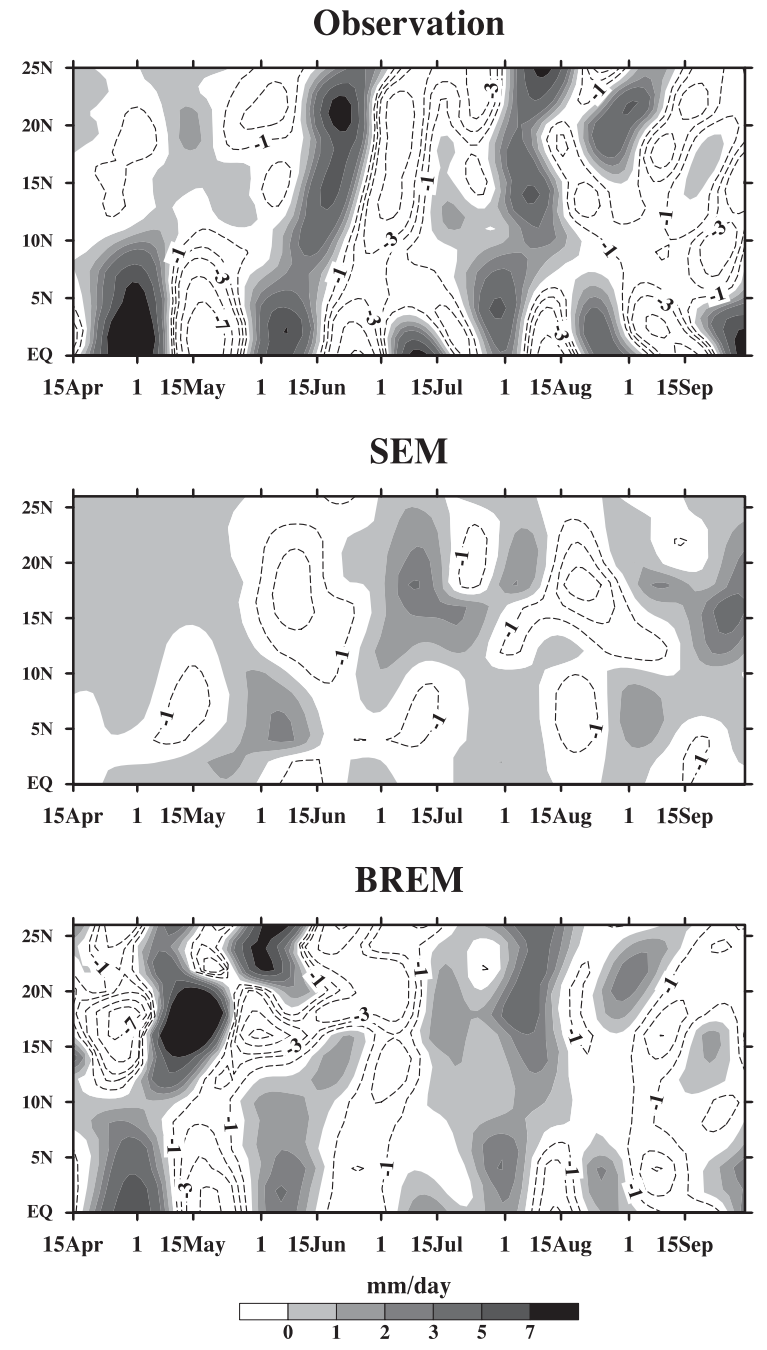

Fig. 10. Time-latitude variation of $20-80$ day filtered rainfall averaged over $75^{\circ} \mathrm{E}-85^{\circ} \mathrm{E}$ (shaded) from (a) GPCP data, and (b) simple ensemble mean (SEM) and (c) bias-removed ensemble mean (BREM) simulations.

at all latitudes south of $10^{\circ} \mathrm{N}$ throughout the season, and at northern latitudes after the last week of June. Within $15^{\circ} \mathrm{N}-25^{\circ} \mathrm{N}$ belt, until the first half of June that represents the onset, the active propagations only slightly match with the observation. But from the later part of the major break spell in July, the BREM propagations match better with the observation, especially over the northern latitudes. In particular, the propagation structure after the middle of August, till the withdrawal of monsoon are 
Interannual variation of all-India summer monsoon rainfall

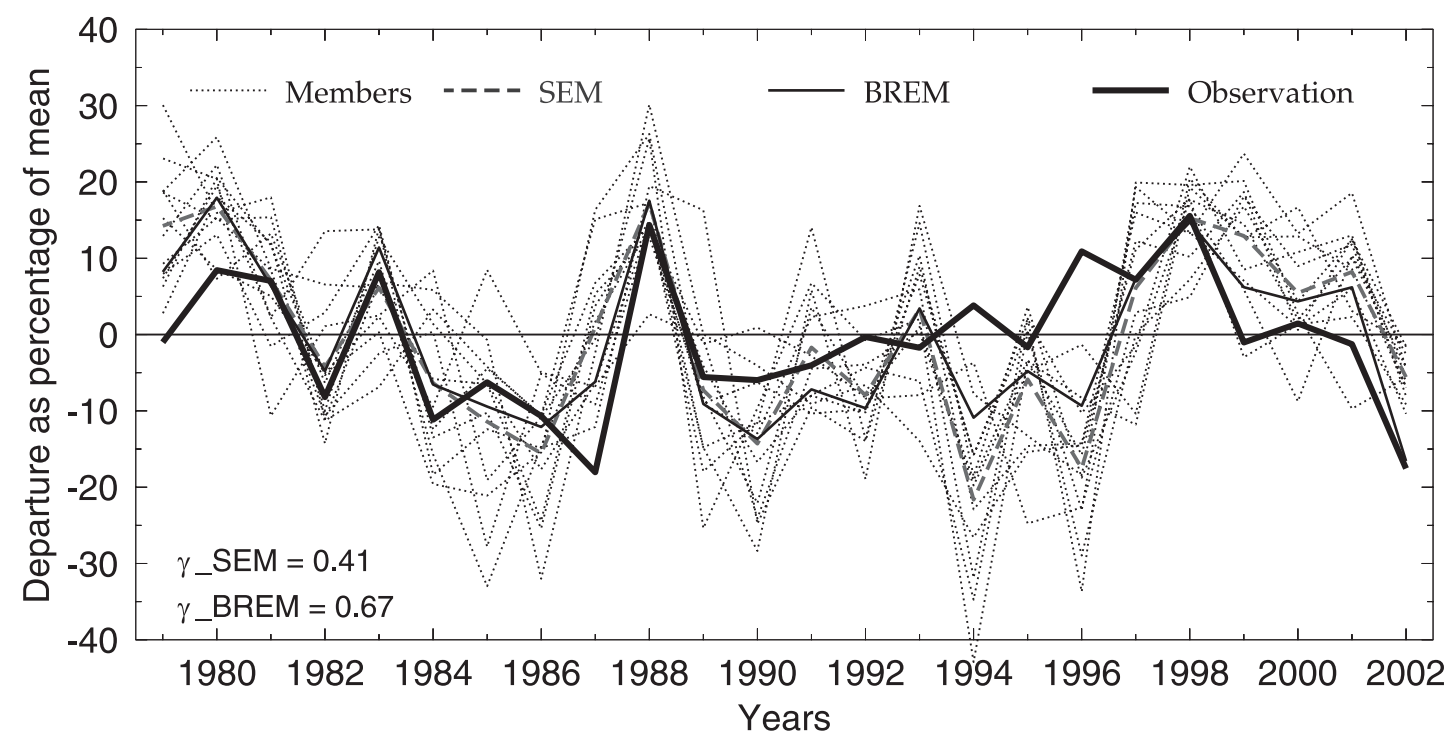

Fig. 11. Interannual variation of ISMR from observation, members and simple ensemble mean (SEM) and bias-removed ensemble mean (BREM). All-India seasonal (JJAS) mean departures are given as the percentage of its long-term mean.

well captured. This indicates that the mean bias-removal helps to improve not only the seasonal mean precipitation response to SST fluctuations, but the pronounced intraseasonal variability of the ISMR as well.

\subsection{Cross-validation}

The skill of the basic model, the bias-removal technique, and the influence of SST boundary fluctuations on monsoon contribute to the success of the BREM in simulating the ISMR variability. The basic model ensemble system exhibits reasonable skill in simulating the interannual variability of ISMR. Figure 11 shows the seasonal mean ISMR anomalies for individual years during the analysis period from the GPCP data, all member simulations, and the SEM and the BREM simulations. It can be seen that the seasonal anomalies associated with most of the extreme events are captured qualitatively, and/or quantitatively by the SEM, and some of the member simulations. This is an important aspect considering the difficulty of many the AGCMs, in simulating the interannual variability of the ISMR (e.g., Gadgil and Sajani 1998).

Better representation of interannual vari- ability in the BREM increases the correlation from 0.41 for the SEM to 0.67. The skill of the BREM can be further improved by incorporating a larger number of training years, and by using more accurate benchmark analysis. For

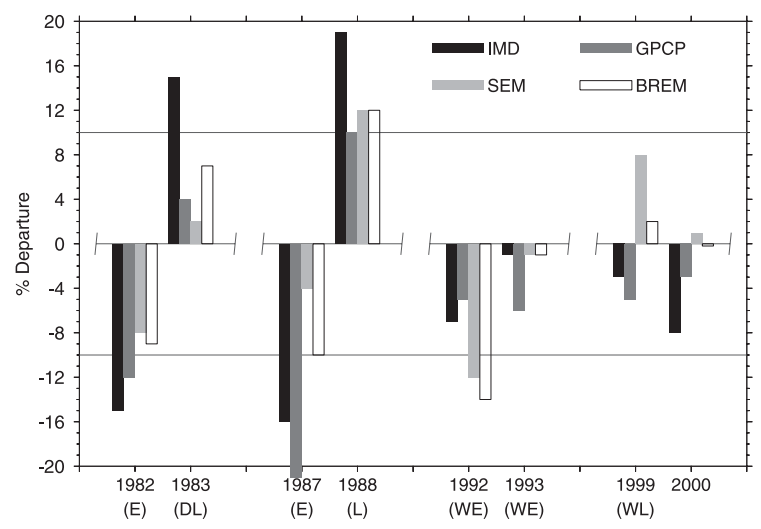

Fig. 12. Seasonal (JJAS) mean departures as percentage of climatological JJAS mean during selected years from IMD observation, observed analysis, simple ensemble mean (denoted as SEM) and bias-removed ensemble mean (denoted as BREM). 
example, Fig. 12 shows the ISMR seasonal (JJAS) departures as percentage of its longterm mean for selected years from the IMD data, the GPCP data and the SEM and the BREM simulations. The disagreement between the benchmark precipitation analysis used in this study (the GPCP data), and the IMD raingauge observation data in these years are significant, which can adversely affect the utility of this methodology for application purposes.

\section{Discussion and conclusions}

The Meteorological Research Institute (MRI) AGCM ensemble simulation of the ISMR, and its variability, is analyzed in this study. The ensemble system consists of 12 integrations of the model forced with observed monthly SST, and sea ice boundary conditions starting from different initial conditions. It is found that climatological aspects important for the simulation of interannual variability of the ISMR, such as the mean ISMR distribution over the Indian region, and the mean seasonal migration of primary rainbelt over the tropical AsiaPacific sector, are achieved by the simple ensemble mean (SEM) simulation. Consequently, the simple ensemble mean shows marked skill in simulating extreme ISMR events concurrent with pronounced large-scale tropical SST fluctuations. However, the SEM still shows some systematic bias in the simulated climatological ISMR pattern, and mean seasonal variation of rainfall over the Asia-Pacific region. Hence the monsoon interannual variability throughout the entire analysis period is not adequately represented.

Systematic bias in the simulation of climatological seasonal variation of rainfall is removed by applying a bias-correction for the member simulations. This was achieved through multiple linear regression of daily precipitation from the member simulations, against an observed benchmark precipitation analysis, during a long training phase, to derive coefficients for each ensemble member which are reset at each local grid, and for each Julian day. For this purpose, the 24-year analysis period is divided into a 23-year training phase, and 1-year forecast phase. In cross validation, each year in the 24year analysis period is considered successively as the forecast phase with the remaining 23 years included in the training phase. Thereaf- ter, in the forecast phase, excluding the training phase, an optimal linear combination of the weighted member simulations yields the biasremoved ensemble mean (BREM) simulation. Removal of bias in the simulation of background climatology, such as the summer mean rainfall pattern over the Indian region, and the seasonal migration of ITCZ over the AsiaPacific sector is found to result in a marked improvement in the ability of the BREM in capturing the interannual variability of the ISMR during the entire analysis period. It is to be noted that, due to the stochastic nature of single model ensemble simulations, with different initial conditions, there is a complex dependence of weights on performance of members. In other words, unlike multimodel ensemble simulations where, the members often experience a systematic bias in tropical precipitation response, in a single model ensemble system, the performance of a member during the forecast phase can be different from its behaviour during the training phase. But the biasremoval methodology, with resetting of member weights in space (grid points) and time (Julian day), using sufficiently long training phase, effectively circumvents the complex dependence of weights, and yields a markedly improved simulation of the ISMR and its variability in the BREM.

The skill of BREM in simulating the ISMR, and its intraseasonal variability, is illustrated by forecasting the extreme drought season of 2002. The effective bias-removal brings out the simulated precipitation response to fluctuations in SST boundary forcing over the tropics. As a result, the BREM is found to markedly improve up on the SEM, not only in capturing the seasonal anomaly of 2002, but its intraseasonal variability to a great extend as well. Apart from illustrating the skill of the BREM, this study underlines the earlier hypothesis that climatological ISMR pattern and seasonal migration of the primary rainbelt over the Asia-Pacific region are necessary for capturing the interannual variation of ISMR. Further, it implies the importance of removal of climatological bias to improve the simulation of subseasonal variation of ISMR.

A consistent understanding of the influence of equatorial Indian Ocean (EQIO) SST anomalies on ISMR and its intraseasonal variability 


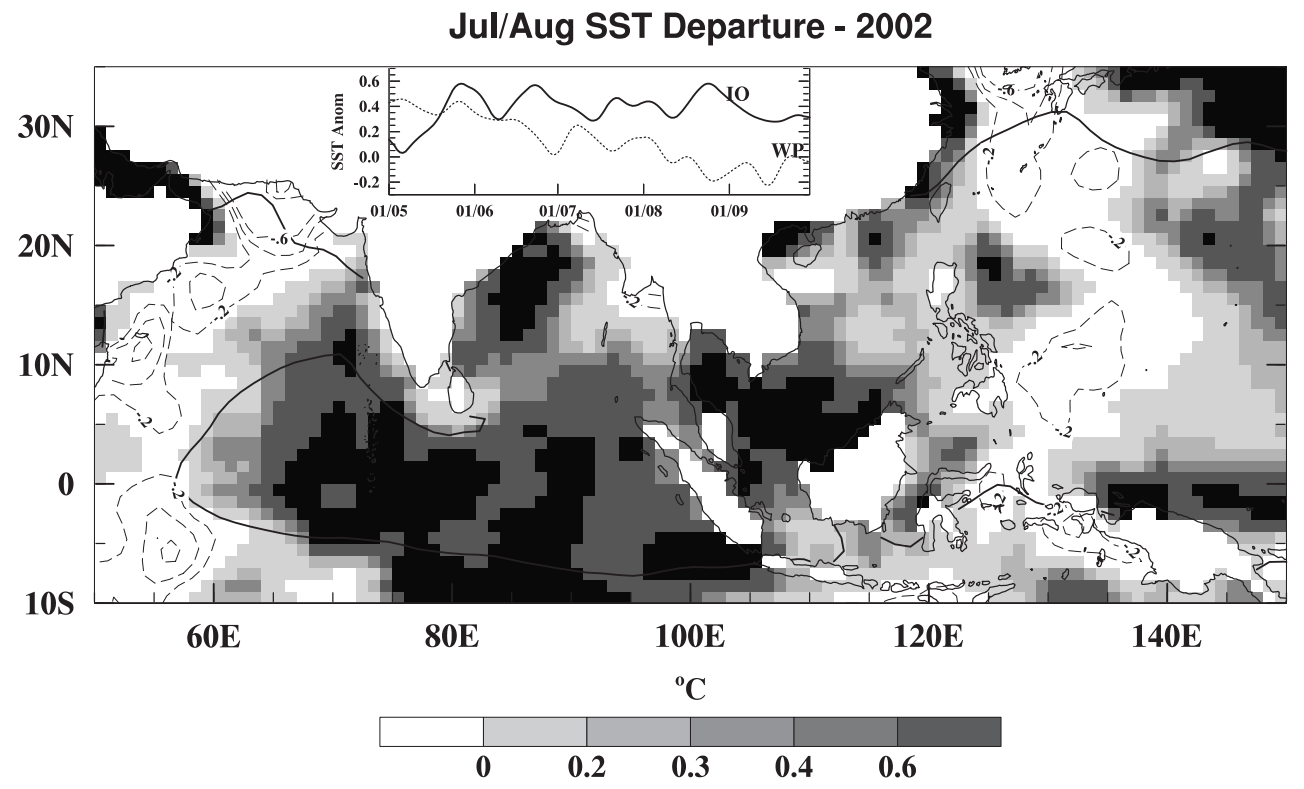

Fig. 13. July/August mean SST departure (positive: shaded; negative: dashed contours) in 2002. Solid line highlights the region with climatological Jul/Aug mean SST greater than $28^{\circ} \mathrm{C}$. Daily SST anomalies averaged over EQIO (denoted as IO) and Western Pacific (denoted as WP) during 2002 is shown in inset.

in 2002 is helpful for interpreting the success of the methodology in 2002 , and for assessing the improved skill of bias-removed ensemble mean. The mean SST departure, during the peak monsoon months of July and August of 2002, based on Reynold's monthly SST shows that the entire equatorial Indian ocean was anomalously warm, with anomalies stronger than that over the western Pacific Ocean (Fig. 13). These anomalies over regions with warm mean SSTs (greater than the basin threshold value of $\sim 28^{\circ} \mathrm{C}$ ) are important for the commencement of organized convection, and can modulate the meridional land-ocean temperature contrast, and the local reverse Hadley circulation, resulting in increased ascent (descent) and convection (subsidence) over the equatorial Indian Ocean (Indian subcontinent). On the seasonal mean time scale, observational and sensitivity studies based on idealized Indian Ocean SST anomalies (Chandrasekar and Kitoh 1998) suggest that rainfall increases (decreases) over the EQIO region of warm (cold) SST anomaly. This was found to be associated with anomalous negative (positive) rainfall departures on the seasonal time scale over the Indian land region, accompanied by the weakening (strengthening) of the cross equatorial flow and monsoon reverse Hadley circulation.

The normalized daily SST anomalies (interpolated from Reynold's weekly SSTs), averaged over EQIO and western Pacific warm pool region (WP, $5^{\circ} \mathrm{S}-5^{\circ} \mathrm{N} ; 120^{\circ} \mathrm{E}-160^{\circ} \mathrm{E}$ ), also show that in spite of subseasonal fluctuations, warm SST anomalies persist over EQIO throughout the season (Fig. 13 inset). These anomalies are larger than the anomalies over the WP, especially in later months of the season, when weak warm El Niño anomalies started developing in the Central Pacific. This can affect both the monsoon reverse Hadley circulation over the Indian sector, and the Walker circulation along the Asia-Pacific sector, resulting in EQIO having anomalously stronger convection compared to the Indian landmass and the West Pacific warm pool regions. This indicates that SST anomalies over the equatorial Indian Ocean played a decisive role in the long and intense break in the peak monsoon month of July, which primarily led to the deficient seasonal summer monsoon rainfall of 2002. Thus, in addition to the effective bias-removal, the 
pronounced influence of equatorial SST fluctuations on modulating the strength of the 2002 monsoon, played a crucial role in the success of the methodology in this season.

A major factor crucial for the marked improvement in BREM in capturing the forced atmospheric response, is the basic skill of the model ensemble system, to simulate ISMR, and its variability from intraseasonal to interannual time scales. However, the low-frequency intraseasonal variation associated with northward propagations in bias-removed ensemble mean, still needs further improvement to match with the observation. Inclusion of more years, in the training phase can improve this aspect. Another major factor limiting the skill in simulating northward propagations is the absence of a self-evolving, or intraseasonally varying SSTs (which is crucial for low-frequency intraseasonal modes, Rajendran and Kitoh 2006) in the present modeling framework. But the existence of a rather smooth intraseasonal component in the observed monthly SST used for forcing the model, enables the simulation to capture low-frequency ISOs to some extent particularly after the effective climatological biasremoval, using member weights varying locally and for Julian days. Hence, this bias-corrected ensemble system, with a more realistic intraseasonal SST forcing, or when coupled with a skillful ocean GCM, has great application potential for dynamical prediction of Indian summer monsoon rainfall.

\section{Acknowledgments}

Ensemble integrations were performed at MRI by the project "Climate simulation since Industrial Revolution (FY2002-FY2004)" in consent with "Climate of the $20^{\text {th }}$ Century International Project (C20C)". K. Rajendran was supported by the Co-operative Systems for Supporting Priority Research, Japan Science and Technology Agency. We appreciate the comments and suggestions from the anonymous reviewers which were helpful in improving the paper.

\section{References}

Adler, R.F., G.J. Huffman, D.T. Bolvin, S. Curtis, and E.J. Nelkin, 2000: Tropical Rainfall Distributions Determined Using TRMM Combined with Other Satellite and Rain Gauge Information. J. Appl. Meteor., 39, 2007-2023.

Ananthakrishnan, R. and M.K. Soman, 1988: The onset of south-west monsoon over Kerala: 1901-1980. J. Climatol., 8, 283-296.

Chandrasekar, A. and A. Kitoh, 1998: Impact of localized sea surface temperature anomalies over the equatorial Indian Ocean on the Indian summer monsoon. J. Meteor. Soc. Japan, 76, 841-853.

Charney, J.G. and J. Shukla, 1981: Predictability of monsoons. In Monsoon Dynamics. Eds. J. Lighthill and $R$ P Pearce. Cambridge University Press.

Duchon, C.E., 1979: Lanczos filtering in one and two dimensions. J. Appl. Meteor., 18, 1016-1022.

Fennessy, M.J., J.L.K. III, B. Kirtman, L. Marx, S. Nigam, E. Schneider, J. Shukla, D. Straus, A. Vernekar, Y. Xue, and J. Zhou, 1994: The simulated Indian monsoon: A GCM sensitivity study. J. Climate, 7, 33-43.

Flatau, M., P.J. Flatau, and D. Rudnick, 2001: The dynamics of double monsoon onsets. J. Climate, 14, 4130-4146.

Flatau, M.K., P.J. Flatau, J. Schmidt, and G.N. Kiladis, 2003: Delayed onset of the 2002 Indian monsoon. Geophys. Res. Lett., 30 (14), 1768, doi:10.1029/2003GL017,434.

Gadgil, S. and S. Sajani, 1998: Monsoon precipitation in the AMIP runs. Climate Dyn., 14, 659689.

Goswami, B.N., 1998: Interannual variations of Indian summer monsoon in a GCM: External conditions versus internal feedbacks. J. Climate, 11, 501-522.

Goswami, B.N., V. Krishnamurthy, and H. Annamalai, 1999: A broad-scale circulation index for the interannual variability of the Indian summer monsoon. Quart. J. Roy. Meteor. Soc., 125, 611-633.

Hansen, J. and Co-authors, 2002: Climate forcings in Goddard Institute for Space Studies SI2000 simulation. J. Geophys. Res., 107.

Joseph, P.V., J.K. Eischeid, and R.J. Pyle, 1994: Interannual variability of the onset of the Indian summer monsoon and its association with atmospheric features, El Niño and sea surface temperature anomalies. J. Climate, 7, 81-105.

Ju, J. and J.M. Slingo, 1995: The Asian summer monsoon and ENSO. Quart. J. Roy. Meteor. Soc., 121, 1133-1168.

Kalnay, E. and Co-authors, 1996: The NCEP/NCAR 40-year reanalysis project. Bull. Amer. Meteor. Soc., 77, 437-471.

Kang, I.S. and Co-authors, 2002: Intercomparison of the climatological variations of Asian summer 
monsoon precipitation simulated by 10 GCMs. Climate Dyn., 19, 383-395.

Kawamura, R., 1998: A possible mechanism of the Asian summer monsoon-ENSO coupling. $J$. Meteor. Soc. Japan, 76, 1009-1027.

Krishnamurti, T.N., C.M. Kishtawal, T.E. LaRow, D.R. Bachiochi, Z. Zhang, C.E. Williford, S. Gadgil, and S. Sajani, 1999: Improved weather and seasonal climate forecasts from multimodel superensemble. Science, 285, 1548-1550.

Krishnamurti, T.N., C.M. Kishtawal, Z. Zhang, T.E. LaRow, D.R. Bachiochi, C.E. Williford, S. Gadgil, and S. Sajani, 2000: Multimodel ensemble forecasts for weather and seasonal climate. J. Climate, 13, 4196-4216.

Krishnamurti, T.N., S. Sajani, D.W. Shin, R.J. Correa-Torres, T.S.V.V. Kumar, E. Williford, C. Kummerow, R.F. Adler, J. Simpson, R. Kakar, W.S. Olson, and F.J. Turk, 2001: Realtime multianalysis-multimodel sperensemble forecasts of precipitation using TRMM and SSM/I products. Mon. Wea. Rev., 129, 2861-2883.

Parthasarathy, B., A.A. Munot, and D.R. Kothawale, 1994: All-India monthly and seasonal rainfall series: 1871-1993. Theor. Appl. Climatol., 49, 217-224.

Rajeevan, M., D.S. Pai, S.K. Dikshit, and R.R. Kelkar, 2004: IMD's new operations models for long range forecast of southwest monsoon rainfall over India and their verification for 2003. Current Science, 86, 422-431.

Rajendran, K. and A. Kitoh, 2006: Modulation of tropical intraseasonal oscillations by ocean atmosphere coupling. J. Climate, 19, 366-391.

Rayner, N.A., D.E. Parker, E.B. Horton, C.K. Folland, L.V. Alexander, D.P. Rowell, E.C. Kent, and A. Kaplan, 2003: Global analyses of SST, sea ice and night marine air temperature since the late $19^{\text {th }}$ century. J. Geophys. Res., 108, doi:10.1029/2002JD002,670.

Reynolds, R.W. and T.M. Smith, 1994: Improved global sea surface temperature analysis using optimum interpolation. J. Climate, 7, 929948.

Reynolds, R.W., N.A. Rayner, T.M. Smith, D.C. Stokes, and W. Wang, 2002: An improved in situ and satellite SST analysis for climate. J. Climate, 15, 1,609-1,625.

Sajani, S., S.N. Beegum, and K. Krishnamoorthy, 2007: The role of low-frequency intraseasonal oscillations in the anomalous Indian summer monsoon rainfall of 2002. J. Earth Syst. Sci., 116, 149-157.

Shibata, K., H. Yoshimura, M. Ohizumi, M. Hosaka, and M. Sugi, 1999: A simulation of troposphere, stratosphere and mesosphere with an MRI/JMA98 GCM. Pap. Meteor. Geophys., 50, 15-53.

Shukla, J., 1998: Predictability in the midst of chaos: A scientific basis for climate forecasting. Science, 282, 728-731.

Sikka, D.R. and S. Gadgil, 1980: On the maximum cloud zone and the ITCZ over Indian longitudes during the southwest monsoon. Mon. Wea. Rev., 108, 1840-1853.

Sperber, K.R. and T.N. Palmer, 1996: Interannual tropical rainfall variability in general circulation model simulations associated with the Atmospheric Model Intercomparison Project. J. Climate, 9, 2727-2750.

Waliser, D.E., K.M. Lau, and J.H. Kim, 2003: Potential predictability of the Madden-Julian oscillation. Bull. Amer. Meteor. Soc., 84, 33-50.

Wang, B., Q. Ding, X. Fu, I.S. Kang, K. Jin, J. Shukla, and F.D. Reyes, 2005a: Fundamental challenge in simulation and prediction of summer monsoon rainfall. Geophys. Res. Lett., 32, L1577, doi:10.1029/2005GL022,734.

Wang, B., P.J. Webster, and H. Teng, 2005b: Antecedents and self-induction of active-break south Asian monsoon unraveled by satellites. Geophys. Res. Lett., 32, L04,704, doi:10.1029/ 2004GL020,996.

Webster, P.J., V.O. Magana, T.N. Palmer, J. Shukla, R.A. Tomas, M. Yanai, and T. Yasunari, 1998: Monsoons: Processes, predictability, and the prospects for prediction. J. Geophys. Res., 103, 14,451-14,510.

Xie, P., J.E. Janowiak, P.A. Arkin, R. Adler, A. Gruber, R. Ferraro, G.J. Huffman, and S. Curtis, 2003: GPCPC pentad precipitation analyses: An experimental dataset based on gauge observations and satellite estimates. J. Climate, 16, 2197-2214.

Yasunari, T., 1979: Cloudiness fluctuations associated with the Northern Hemisphere summer monsoon. J. Meteor. Soc. Japan, 57, 227-242.

Yasunari, T., 1981: Structure of the Indian monsoon system with around 40-day period. J. Meteor. Soc. Japan, 59, 225-229. 